\title{
Antiepileptic drugs for the primary and secondary prevention of seizures after subarachnoid haemorrhage (Review)
}

\author{
Marigold R, Günther A, Tiwari D, Kwan J
}

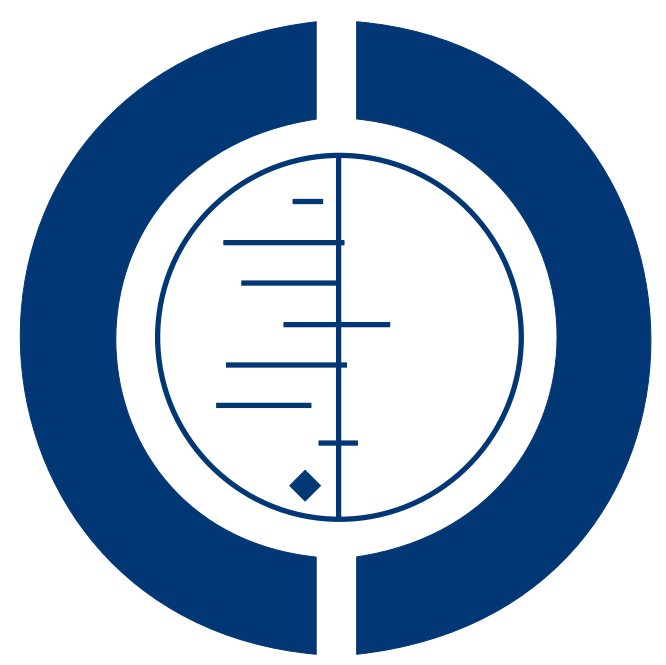

\section{THE COCHRANE COLLABORATION $^{\circledR}$}

This is a reprint of a Cochrane review, prepared and maintained by The Cochrane Collaboration and published in The Cochrane Library 2013, Issue 6

http://www.thecochranelibrary.com

\section{WILEY}

Antiepileptic drugs for the primary and secondary prevention of seizures after subarachnoid haemorrhage (Review)

Copyright $\odot 2013$ The Cochrane Collaboration. Published by John Wiley \& Sons, Ltd. 
TABLE OF CONTENTS

HEADER . . . . . . . . . . . . . . . . . . . . . . . . . . . . . . . . . . . . . . . 1

ABSTRACT . . . . . . . . . . . . . . . . . . . . . . . . . . . . . . . . . . . . . . . . . . . .

PLAIN LANGUAGE SUMMARY . . . . . . . . . . . . . . . . . . . . . . . . . . . . . . . . . . 2

BACKGROUND . . . . . . . . . . . . . . . . . . . . . . . . . . . . . . . . . . . . . . . . .

OBJECTIVES . . . . . . . . . . . . . . . . . . . . . . . . . . . . . . . . . . . . . . . $4 \begin{gathered}4 \\ \text { O }\end{gathered}$

METHODS . . . . . . . . . . . . . . . . . . . . . . . . . . . . . . . . . . . . . . . .

RESULTS . . . . . . . . . . . . . . . . . . . . . . . . . . . . . . . . . . . . . 5

Figure 1. . . . . . . . . . . . . . . . . . . . . . . . . . . . . . . . . . . 6

DISCUSSION . . . . . . . . . . . . . . . . . . . . . . . . . . . . . . . . . . . . .

AUTHORS' CONCLUSIONS . . . . . . . . . . . . . . . . . . . . . . . . . . . . . . . . .

ACKNOWLEDGEMENTS . . . . . . . . . . . . . . . . . . . . . . . . . . . . . . . . . . . . . .

REFERENCES . . . . . . . . . . . . . . . . . . . . . . . . . . . . . . . . . . . . .

CHARACTERISTICS OF STUDIES . . . . . . . . . . . . . . . . . . . . . . . . . . . . . . . . . . . . . . . . .

DATA AND ANALYSES . . . . . . . . . . . . . . . . . . . . . . . . . . . . . . . . . . . . . . . . . $\quad . \quad 11$

CONTRIBUTIONS OF AUTHORS . . . . . . . . . . . . . . . . . . . . . . . . . . . . . . . . . . . . . . . .

DECLARATIONS OF INTEREST . . . . . . . . . . . . . . . . . . . . . . . . . . . . . . . 11

SOURCES OF SUPPORT . . . . . . . . . . . . . . . . . . . . . . . . . . . . . . . . . . 11

INDEX TERMS . . . . . . . . . . . . . . . . . . . . . . . . . . . . . . . . . . . . 11

Antiepileptic drugs for the primary and secondary prevention of seizures after subarachnoid haemorrhage (Review)

Copyright $\odot 2013$ The Cochrane Collaboration. Published by John Wiley \& Sons, Ltd. 


\title{
[Intervention Review]
}

\section{Antiepileptic drugs for the primary and secondary prevention of seizures after subarachnoid haemorrhage}

\author{
Richard Marigold ${ }^{1}$, Albrecht Günther ${ }^{2}$, Divya Tiwari ${ }^{3}$, Joseph Kwan ${ }^{4}$ \\ ${ }^{1}$ Department of Stroke Medicine, Royal Bournemouth Hospital, Bournemouth, UK. ${ }^{2}$ Department of Neurology, Jena University \\ Hospital, Jena, Germany. ${ }^{3}$ Royal Bournemouth Hospital, Bournemouth, UK. ${ }^{4}$ School of Health and Social Care, Bournemouth \\ University, Bournemouth, UK \\ Contact address: Joseph Kwan, School of Health and Social Care, Bournemouth University, Royal London House, Christchurch Road, \\ Bournemouth, Dorset, BH1 3LT, UK. joseph.kwan@rbch.nhs.uk. \\ Editorial group: Cochrane Epilepsy Group. \\ Publication status and date: New, published in Issue 6, 2013. \\ Review content assessed as up-to-date: 12 March 2013.
}

Citation: Marigold R, Günther A, Tiwari D, Kwan J. Antiepileptic drugs for the primary and secondary prevention of seizures after subarachnoid haemorrhage. Cochrane Database of Systematic Reviews 2013, Issue 6. Art. No.: CD008710. DOI: 10.1002/14651858.CD008710.pub2.

Copyright (C) 2013 The Cochrane Collaboration. Published by John Wiley \& Sons, Ltd.

\section{A B S T R A C T}

\section{Background}

Subarachnoid haemorrhage may result in seizures both acutely and in the longer term. The use of antiepileptic drugs (AEDs) in the primary and secondary prevention of seizures after subarachnoid haemorrhage is uncertain, and there is currently no consensus on treatment.

\section{Objectives}

To assess the effects of AEDs for the primary and secondary prevention of seizures after subarachnoid haemorrhage.

\section{Search methods}

We searched the Cochrane Epilepsy Group Specialised Register, the Cochrane Central Register of Controlled Trials (CENTRAL) (2013, Issue 1) in The Cochrane Library, and MEDLINE (1946 to 12th March 2013). We checked the reference lists of articles retrieved from these searches.

\section{Selection criteria}

We considered all randomised and quasi-randomised controlled trials in which patients were assigned to a treatment (one or more AEDs) or placebo.

\section{Data collection and analysis}

Two review authors (RM and JK) independently screened and assessed the methodological quality of the studies. If studies were included, one author extracted the data and the other checked it.

\section{Main results}

No relevant studies were found.

Antiepileptic drugs for the primary and secondary prevention of seizures after subarachnoid haemorrhage (Review)

Copyright $\odot 2013$ The Cochrane Collaboration. Published by John Wiley \& Sons, Ltd. 


\section{Authors' conclusions}

There was no evidence to support or refute the use of antiepileptic drugs for the primary or secondary prevention of seizures related to subarachnoid haemorrhage. Well-designed randomised controlled trials are urgently needed to guide clinical practice.

\section{PLAIN LANGUAGE SUMMARY}

\section{Antiepileptic drugs for the primary and secondary prevention of seizures after subarachnoid haemorrhage}

The purpose of this review was to examine whether the routine use of antiepileptic medication in preventing epileptic seizures following subarachnoid haemorrhage can be justified. This includes patients who have not yet had a seizure (primary prevention) and those who have already had one (secondary prevention).

Epileptic seizures are caused by abnormal, rhythmic discharges of nerve cells within the brain leading to involuntary changes in body movement or function, sensation, awareness, or behaviour. Following a subarachnoid haemorrhage seizures can occur in up to $25 \%$ of patients, triggered by nerve cell damage caused by the blood itself, the formation of scar tissue, and swelling around the site of bleeding. Recurrent uncontrolled seizures can cause considerable morbidity and mortality, preventing neurological recovery and reducing quality of life. Conversely, side effects of antiepileptic medication include diarrhoea, nausea and vomiting, drowsiness, dizziness, agitation, tremor, confusion and skin rash. These need to be considered when prescribing antiepileptic medication, as the medication itself may hinder neurological recovery and rehabilitation.

To date there have been no randomised controlled trials comparing antiepileptic drugs with placebo following subarachnoid haemorrhage. Some retrospective studies have suggested worse outcomes in patients on higher doses and a longer duration of antiepileptic treatment, as explained in the review, but they do not provide the strength of evidence required for their use as a routine recommendation.

Currently, there is insufficient evidence to justify the routine use of antiepileptic medication for the primary and secondary prevention of seizures after subarachnoid haemorrhage, and a double blind randomised controlled trial comparing antiepileptic medication with placebo would help to clarify this important question.

\section{B A C K G ROU N D}

\section{Description of the condition}

Subarachnoid haemorrhage (SAH) occurs when blood is released into the subarachnoid space that surrounds the brain and spinal cord (Van Gijn 2001). Although SAH accounts for only 3\% of all strokes, it is associated with $5 \%$ of all stroke deaths, and for more than $25 \%$ of potential life years lost through stroke (Van Gijn 2001). Significant developments have taken place in the management of SAH in the past three decades, including the use of early angiography, endovascular coil embolisation and more sophisticated intensive care support (Butzkueven 2000). Consequently, the outcome of patients with SAH has improved substantially. In the 1970 s, the early mortality rate after SAH was as high as $65 \%$ (Fogelholm 1981), but in recent years it has fallen to between $20 \%$ and 30\% (Qureshi 2005). However, 50\% of long-term survivors are still permanently disabled (Claassen 2003).

Seizures and epilepsy are well recognised complications after $\mathrm{SAH}$. Seizures can occur at different time points after SAH:

a. 'onset' seizures occur around the time of the initial haemorrhage; b. 'early' seizures occur during the first two weeks of recovery after SAH or surgery;

c. 'late' seizures occur after the first two weeks of recovery postSAH or following surgery (Bederson 1997; Buczacki 2004).

However, the definitions of early and late seizures differ between authors, and there is conflicting evidence on whether onset seizures predict late seizures or post-SAH epilepsy (Butzkueven 2000; Byrne 2003). Post-SAH epilepsy refers to the condition where at least two spontaneous seizures occur (some have specified that they should be separated by at least 24 hours) after the first few months following the initial SAH or operation (Buczacki 2004; Lin 2003). One study found that post-SAH epilepsy was more frequent in 
patients with severe residual neurological impairment (the risk of developing epilepsy was $28 \%$ at one year and $47 \%$ at four years) compared with patients who had mild or no impairment (the risk was $12 \%$ at one year and $15 \%$ at four years) (Olafsson 2000). The majority of post-SAH seizure types are secondary generalised tonic-clonic seizures or simple partial seizures (Claassen 2003; Lin 2003). Pinto 1996 reported that although early post-SAH seizures did not predict longer-term prognosis, they were related to a higher risk of re-bleeding, death or dependency by the time of hospital discharge. However, other studies have not found such an association (Sundaram 1986).

The incidence of post-SAH seizures varies widely between observational studies mainly as a result of differences in the patient selection methods, the definitions used to describe the timing of postSAH seizures, and the administration of prophylactic antiepileptic drugs (AEDs) after admission. In a previous literature review (Lin 2003), $4 \%$ to $26 \%$ of patients with SAH had onset seizures, $1 \%$ to $28 \%$ had early seizures (within the first two weeks) and $1 \%$ to $35 \%$ had late seizures (after two weeks) (Byrne 2003; Lin 2003). Modern techniques, such as continuous electroencephalogram (EEG) monitoring, have assisted with the less common diagnosis of nonconvulsive seizures and non-convulsive status epilepticus (Vespa 2005). In one study, $18 \%$ of the patients admitted to neurological intensive care units with SAH had non-convulsive seizures (Claassen 2004). Another study reported that $3 \%$ of such patients were in non-convulsive status epilepticus (Dennis 2002), and this should be considered in patients with poor neurological status or deterioration (Lanzino 2011).

Risk factors associated with the occurrence of post-SAH seizures include increasing age, a history of hypertension, poor neurological grade (for example Hunt and Hess grade > 3), the presence of an anterior circulation aneurysm (especially middle cerebral artery aneurysms), the volume of subarachnoid blood and occurrence of aneurysmal re-bleeding, vasospasm, cerebral infarction, subdural haematoma, hyponatraemia and hydrocephalus (Claassen 2003; Lin 2003; Ohman 1990). Intracranial aneurysm treatment, either by neurosurgical clipping or endovascular coiling, has a seizure rate of about 2\% (Lanzino 2011). Unruptured aneurysms treated with surgical clipping have reported seizure rates of $9.2 \%$ to $13 \%$, whereas with coiling this ranges between $6.2 \%$ and $8.3 \%$ (Hart 2011; Hoh 2011). Endovascular intervention had lower seizure rates $(1.3 \%$ to $3.3 \%)$ compared with surgery $(2.2 \%$ to $5.2 \%)$ in the first year (Hart 2011; Molyneux 2005).

\section{Description of the intervention}

There is substantial variability among physicians in the use of AEDs for patients after SAH (Rhoney 2000). Some physicians recommend using prophylactic AEDs for all patients with SAH, especially those undergoing open aneurysmal surgery (King 1994; Ohkuma 1990; Olafsson 2000). Others recommend using AEDs for the in-hospital stay, but not beyond discharge (Varelas 2004).
A third approach recommends targeting AEDs to patients with risk factors that predict future seizure (Butzkueven 2000). Some clinicians do not recommend the routine use of AEDs following SAH (Buczacki 2004; Byrne 2003; Claassen 2003), suggesting that further randomised controlled trials are required (Lin 2003; Rapaport 2012; Rhoney 2000). This lack of consensus stems from uncertainty regarding the need for AEDs, the best AED to use, which patients should receive prophylactic AEDs, and the optimal dosage and duration of treatment (Rapaport 2012; Rhoney 2000; Riordan 2010).

\section{How the intervention might work}

The intervention might work if, in offering routine prophylaxis to patients with SAH, the risk of seizures exceeded the risk of AED-related adverse effects. Why is seizure prevention important? There is conflicting evidence about whether or not in-hospital post-SAH seizures are associated with a poor functional outcome. Some studies have suggested seizures correlate with poorer outcomes (Butzkueven 2000; Claassen 2003). In 247 patients admitted to a neurological intensive care unit with SAH, the occurrence of in-hospital seizures was an independent predictor of oneyear mortality (65\% with seizures versus $23 \%$ without seizures) (Claassen 2003). This may reflect the severity of the SAH itself, as one retrospective study showed that the higher the grade of SAH, the greater the likelihood of seizure, but there was little association with a poorer prognosis at one year (Lin 2008). Why are AEDrelated adverse effects significant? Some authors have suggested that poor patient recovery might actually be caused by AED treatment itself, particularly with phenytoin, rather than seizure activity (Claassen 2003; Naidech 2005; Rosengart 2007). A number of studies have assessed neurological outcomes following short and long-term phenytoin treatment (Chumnanvej 2007; Naidech 2005). Poorer outcomes were associated with higher doses and longer duration of phenytoin treatment. In comparing levetiracetam with phenytoin, levetiracetam use resulted in a higher shortterm seizure recurrence (Murphy-Human 2011), but better longterm neurological outcomes and fewer adverse effects (Lewis 2009; Szaflarski 2010). There is also evidence from animal and human studies that the administration of certain AEDs after brain injury (including stroke and SAH) might lower the chance of a good functional recovery (Brailowsky 1986; Claassen 2003; Naidech 2005).

\section{Why it is important to do this review}

It is important to do this review to establish whether the use of AEDs in seizure prevention post-SAH can be justified, given the morbidity and mortality associated with untreated epileptic seizures and the potential adverse effects of AED treatment. 


\section{O B J E C T I V E S}

The main aim was to assess the effects of AEDs for the primary and secondary prevention of seizures after SAH. For primary prevention, we examined whether AEDs reduced the likelihood of seizures in patients who had had an SAH, but not had a seizure. For secondary prevention, we examined whether AEDs reduced the likelihood of further seizures in patients who had had an SAH and at least one post-SAH seizure.

\section{METHODS}

\section{Criteria for considering studies for this review}

\section{Types of studies}

We considered all randomised and quasi-randomised controlled trials in which patients were assigned to a treatment group (that is receiving at least one $\mathrm{AED}$ ) or a control group (that is receiving placebo or no treatment).

\section{Types of participants}

For a detailed description of the internationally accepted definitions for seizures and epilepsy, please refer to Fisher 2005; for the different types of epileptic seizures, please refer to Engel 2001 and Engel 2006 (by the International League Against Epilepsy). In this review, we considered all studies that recruited patients with a diagnosis of SAH, regardless of whether they had or had not had post-SAH seizures. The diagnosis of SAH was confirmed by neuroimaging using computed tomography $(\mathrm{CT})$ or magnetic resonance (MR) imaging, with or without lumbar puncture (Van Gijn 2001). Studies that exclusively recruited patients with cerebral infarction, primary intracranial haemorrhage, intracranial venous thrombosis or non-stroke conditions (including subdural haemorrhage, extradural haemorrhage, infection- or tumour-related infarction or haemorrhage) were excluded. Patients with a history of epilepsy were excluded. In cases where studies recruited a mixture of patients with and without a history of epilepsy, attempts were made to extract only the results related to those patients without a history of epilepsy.

Children or adults with clinically overt generalised or focal seizures were included, regardless of whether EEG monitoring was used to confirm the diagnosis. For studies that included patients with nonconvulsive seizures diagnosed only by EEG (Bearden 2008), the results for these patients were extracted and analysed separately. In cases where studies recruited patients who had prior neurosurgical procedures (for example aneurysmal clipping or coil embolisation) for $\mathrm{SAH}$, the results for these patients were extracted and analysed separately from those of patients who had not received neurosurgery.

\section{Types of interventions}

The AEDs included were: carbamazepine, clobazam, clonazepam, diazepam, ethosuximide, gabapentin, lamotrigine, levetiracetam, lorazepam, oxcarbazepine, phenytoin, phenobarbitone, primidone, sodium valproate, tiagabine, topiramate, vigabatrin and zonisamide. We considered all trials in which the intervention was compared with a placebo or no treatment. Studies comparing different AEDs were excluded.

\section{Types of outcome measures}

\section{Primary outcomes}

1. Proportion of patients who experienced clinical seizures in the scheduled follow-up period. In cases where seizures occurred, we noted their nature (generalised or focal), timing and whether an EEG was performed to aid the diagnosis and seizure classification.

2. Proportion of patients with a previous seizure who achieved remission for a predefined period of time (e.g. 12 or 24 months).

3. Proportion of patients who withdrew from the allocated treatment within the scheduled follow-up period. This was a composite outcome that took into account several factors, including adverse events, compliance and effectiveness of treatment. We were particularly interested in the occurrence of side effects for the different AEDs, which might be physical or neurobehavioural (e.g. problems with memory, attention and performance skills).

4. Proportion of patients who had either died or were dependent at the end of the scheduled follow-up period. 'Independent' individuals were defined as those who did not require regular physical assistance from another person for activities of daily living such as mobility, dressing, transfers and feeding. 'Dependent' individuals were those who failed to meet one or more of these criteria.

\section{Other outcomes of interest}

1. Quality of life (e.g. using a recognised scoring system such as the Short Form-36 (SF-36) or EuroQol).

2. Duration of stay for the acute phase of stroke recovery.

3. 'Optimal' duration of treatment (i.e. the length of time that the intervention should be administered). 


\section{Search methods for identification of studies}

This review drew on the search strategies developed for the Cochrane Epilepsy Group and identified relevant studies in the Cochrane Epilepsy Group Specialized Register.

We searched the following databases:

1. Cochrane Epilepsy Group Specialized Register (15 March 2013) using the search strategy outlined in Appendix 1;

2. the Cochrane Central Register of Controlled Trials (CENTRAL) (2013, Issue 1) in The Cochrane Library using the search strategy outlined in Appendix 2; and

3. MEDLINE (Ovid) (1946 to 12 March 2013) using the search strategy outlined in Appendix 3.

We also checked the reference lists of articles retrieved from the above searches.

\section{Data collection and analysis}

\section{Selection of studies}

One review author (RM) screened the titles, abstracts and keywords of publications identified by the searches to assess their eligibility. Publications that did not meet the inclusion criteria were excluded at this stage. A paper copy of the full publication of each study that was relevant was obtained. Two review authors (RM and $\mathrm{JK}$ ) assessed these studies according to pre-specified selection criteria.

\section{Data extraction and management}

One review author (RM) recorded the data on an extraction form. Another review author (JK) independently checked the extracted data. Data reported by the published sources were used for analyses in this review. We extracted demographic data (for example total number of participants randomly assigned, number of participants per group, and age and sex of participants) and possible confounding factors (for example timing of randomisation, method of SAH diagnosis, level of sedation after surgery, location of aneurysm, severity of neurological deficit, presence of vasospasm or secondary cerebral infarction, history of epilepsy, other comorbid disorders, number of patients who were lost to follow-up, duration of followup, and method of treatment, such as aneurysmal clipping or coil embolisation).

\section{Assessment of risk of bias in included studies}

Two review authors (RM and JK) independently assessed the methodological quality of all the included studies and recorded the findings. We noted the important aspects of methodology: study design, type of control, method of allocation concealment, completeness of follow-up, and the presence of blinding for assessments of non-fatal outcomes.

\section{Data synthesis}

Data analysis was designed according to the guidelines set out by The Cochrane Collaboration regarding statistical methods. Primary analyses were by intention to treat. For dichotomous data, we expressed the relative treatment effects as an odds ratio with $95 \%$ confidence interval. For continuous data, we calculated the weighted mean difference with $95 \%$ confidence interval. A P value of less than 0.05 was considered statistically significant. Clinical heterogeneity was assessed by the distribution of demographic and prognostic variables across the treatment and control groups. Statistical heterogeneity among the studies was tested using the $\mathrm{I}^{2}$ statistic. In cases where the results could be sensibly combined and there was no significant clinical or statistical heterogeneity, a meta-analysis was undertaken using a fixed-effect or random-effects model, or both. Sensitivity analyses were undertaken to test the robustness of the meta-analysis as described above. The influence of the following factors on the overall results was assessed: methodological quality, excluding the study with the smallest or largest sample size, and removing the study with the smallest or largest treatment effects.

\section{RES U L T S}

\section{Description of studies}

\section{Results of the search}

A total of 194 studies were identified by the search: 50 records were screened, 42 were initially excluded, and the remaining eight were excluded with reasons following analysis of the full texts. The eight studies were excluded due to lack of randomisation of the AED versus placebo, and most of these studies were retrospective analyses. Consequently, no studies met the inclusion criteria, see Figure 1. 
Figure I. Study flow diagram.

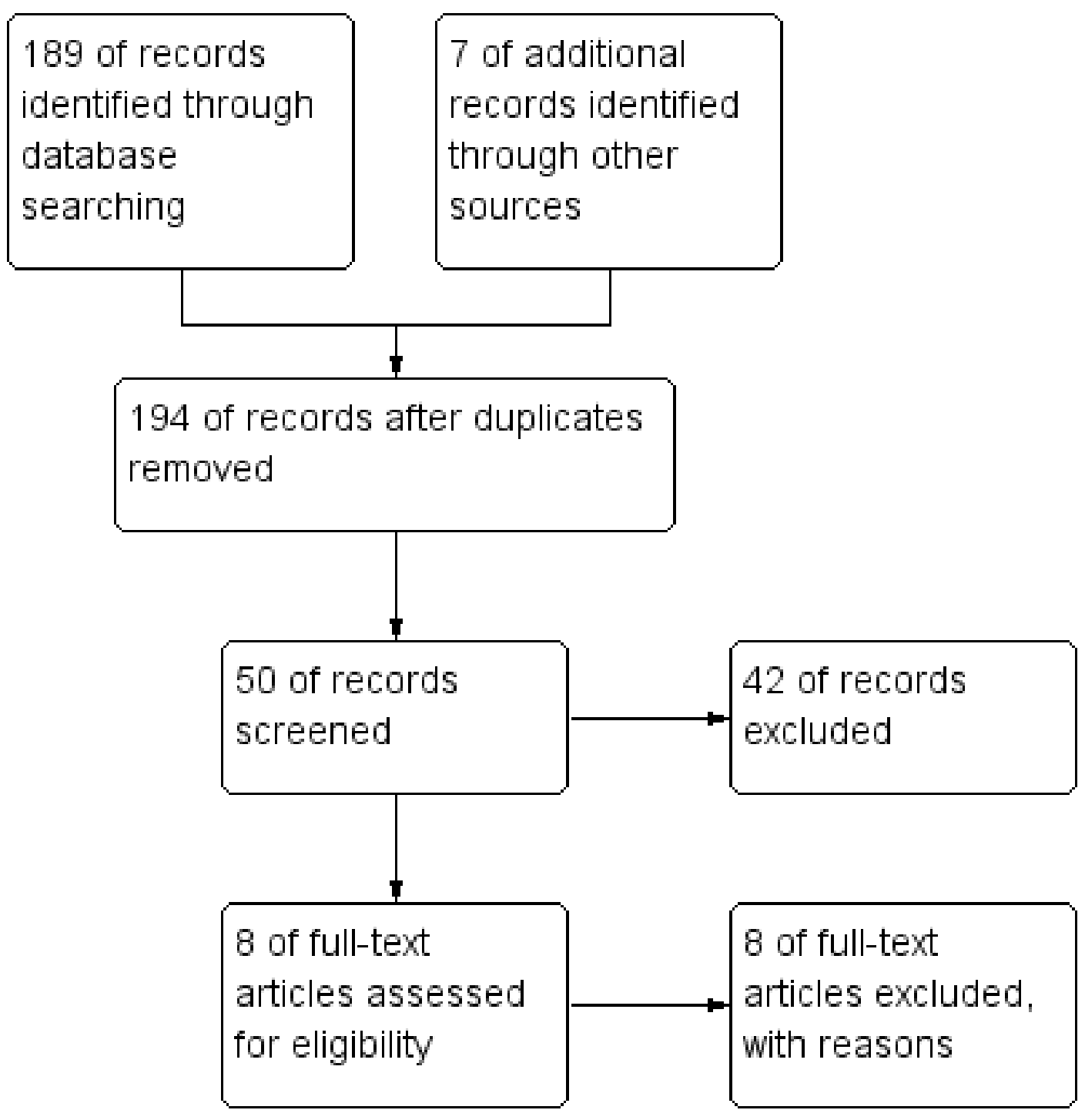

\section{Excluded studies}

No studies provided a randomised controlled trial of an AED versus placebo, but there were a number of retrospective analyses which provided useful information upon which future randomised studies could be based. See Characteristics of excluded studies.

\section{Risk of bias in included studies}

No studies were included in the review.

\section{Effects of interventions}

No studies met the inclusion criteria.

\section{DISCUSSION}

The purpose of this review was to assess the effects of AEDs for the primary and secondary prevention of seizures after SAH. None of the studies selected in the review could be used for further analysis as there were no randomised or quasi-randomised controlled trials comparing antiepileptic drugs (AEDs) with placebo 
or no drug. As demonstrated by the table of excluded studies, the data that are currently available were mainly limited to retrospective analyses following a change in AED protocol, rather than randomised, placebo controlled trials (Chumnanvej 2007; Murphy-Human 2011; Naidech 2005; Szaflarski 2010). These have limited applicability both due to their retrospective nature and the small number of patients studied.

International guidelines suggest that prophylactic AEDs should not be routinely prescribed, but considered in selected cases. The American Stroke Association (Bederson 2009) states that for aneurysmal SAH, AED prophylaxis may be considered in the posthaemorrhagic period and longer term for those with risk factors for seizure recurrence. This includes prior seizure, parenchymal infarct or haematoma and a middle cerebral artery aneurysm. European Stroke Initiative (ESI) Guidance on intracerebral haemorrhage (Steiner 2006) recommends consideration of prophylactic AEDs for seven days in patients with lobar haemorrhage, after which AED treatment should be stopped. Should seizures recur, the ESI recommends AEDs be restarted and continued for 30 days then stopped following a gradual reduction in dose.

Given the lack of robust evidence to determine best practice, we recommend that a large randomised, double blind, placebo controlled trial is conducted to assess the effectiveness, adverse event profile and optimum duration of AEDs to prevent seizures following SAH. Examples would be double blind randomised trials comparing phenytoin with placebo and levetiracetam with placebo. The results of such studies will then inform decision making in weighing up the benefits of AEDs in both primary and secondary seizure prophylaxis against the risk of long-term adverse neurological, cognitive and functional outcomes.

\section{A U THORS, CONCLUSIONS}

\section{Implications for practice}

Currently, there is insufficient evidence to support the routine use of antiepileptic drugs for the primary or secondary prevention of seizures after subarachnoid haemorrhage.

\section{Implications for research}

More research is needed to assess the efficacy and tolerability of antiepileptic drugs for the primary and secondary prevention of seizures after subarachnoid haemorrhage. Future studies should be randomised double-blind trials comparing one or more AEDs to placebo. These should aim to recruit large numbers of patients and generate answers to the optimal dosing, timing and duration of AED treatment as well as defining side effects and longer-term cognitive and functional outcomes.

\section{ACKNOW LEDGEMENTS}

We are grateful for the input from the Cochrane Epilepsy Group.

\section{R E F E R E N C E S}

\section{References to studies excluded from this review}

Chumnanvej 2007 \{published data only\}

Chumnanvej S, Dunn IF, Kim DH. Three-day phenytoin prophylaxis is adequate after subarachnoid haemorrhage. Neurosurgery 2007;60:99-103.

Lewis 2009 \{published data only\}

Lewis SA, Schmitt S. Levetiracetam: a potential alternative to phenytoin as first line prophylactic anti-epileptic therapy in aneurysmal subarachnoid hemorrhage. Epilepsia 2009; 50:124-5.

Murphy-Human 2011 \{published data only\} Murphy-Human T, Welch E, Zipfel G, Diringer MN, Dhar, R. Comparison of short duration levetiracetam with extended-course phenytoin for seizure prophylaxis after subarachnoid haemorrhage. World Neurosurgery 2011;75 (2):269-74.

Naidech 2005 \{published data only\}

Naidech AM, Kreiter KT, Janjua N, Ostapkovich N, Parra A, Commichau C, et al.Phenytoin exposure is associated with functional and cognitive disability after subarachnoid hemorrhage. Stroke 2005;36(3):583-7.
Rapaport 2012 \{published data only\}

Rapaport B, Zubkov S, Fields M, Marcuse L. Effect of prophylactic antiepileptic drugs on seizures in patients with non traumatic intracranial hemorrhage. Epilepsy Currents 2012;12(1 Suppl 1):1535-97.

Rhoney 2000 \{published data only\} Rhoney DH, Tipps LB, Murry KR, Basham MC, Michael DB, Coplin WM. Anticonvulsant prophylaxis and timing of seizures after aneurysmal subarachnoid hemorrhage. Neurology 2000;55(2):258-65.

Rosengart 2007 \{published data only\} Rosengart AJ, Huo D, Tolentino J, Novakovic RL, Frank JI, Goldenberg FD, et al.Outcome in patients with subarachnoid hemorrhage treated with antiepileptic drugs. Journal of Neurosurgery 2007;107(2):253-60.

Szaflarski 2010 \{published data only\} Szflarski JP, Sangha KS, Lindsell CJ, Shutter LA. Prospective, randomized, single-blinded comparative trial of intravenous levetiracetam versus phenytoin for seizure prophylaxis. Neurocritical Care 2010;12:165-72. 


\section{Additional references}

\section{Bearden 2008}

Bearden S, Eisenschenk S, Uthman B. Diagnosis of nonconvulsive status epilepticus (NCSE) in adults with altered mental status: clinico-electroencephalographic considerations. American Journal of Electroneurodiagnostic Technology 2008;48(1):11-37.

Bederson 1997 Bederson JB. Subarachnoid hemorrhage: pathophysiology and management. Park Ridge: American Association of Neurological Surgeons, 1997. [: ISBN-10 187928443X ]

Bederson 2009

Bederson JB, Sander Connolly Jr E, Hunt Batjer H, Darcey RG, Dion JE, Diringer MN, et al.Guidelines for the management of aneurysmal subarachnoid hemorrhage: a statement for healthcare professionals from a Special Writing Group of the Stroke Council, American Heart Association. Stroke 2009;40:994-1025.

\section{Brailowsky 1986}

Brailowsky S, Knight RT, Efron R. Phenytoin increases the severity of cortical hemiplegia in rats. Brain Research 1986; 376(1):71-7.

\section{Buczacki 2004}

Buczacki SJ, Kirkpatrick PJ, Seeley HM, Hutchinson PJ. Late epilepsy following open surgery for aneurysmal subarachnoid haemorrhage. Journal of Neurology, Neurosurgery, and Psychiatry 2004;75(11):1620-2.

\section{Butzkueven 2000}

Butzkueven H, Evans AH, Pitman A, Leopold C, Jolley DJ, Kaye $\mathrm{AH}$, et al.Onset seizures independently predict poor outcome after subarachnoid hemorrhage. Neurology 2000; 55(9):1315-20.

\section{Byrne 2003}

Byrne JV, Boardman P, Ioannidis I, Adcock J, Traill Z. Seizures after aneurysmal subarachnoid hemorrhage treated with coil embolization. Neurosurgery 2003;52(3):545-52.

\section{Claassen 2003}

Claassen J, Peery S, Kreiter KT, Hirsch LJ, Du EY, Connolly ES, et al.Predictors and clinical impact of epilepsy after subarachnoid hemorrhage. Neurology 2003;60(2):208-14.

\section{Claassen 2004}

Claassen J, Mayer SA, Kowalski RG, Emerson RG, Hirsch LJ. Detection of electrographic seizures with continuous EEG monitoring in critically ill patients. Neurology 2004; 62(10): 1743-8.

\section{Dennis 2002}

Dennis LJ, Claassen J, Hirsch LJ, Emerson RG, Connolly ES, Mayer SA. Nonconvulsive status epilepticus after subarachnoid hemorrhage. Neurosurgery 2002;51(5): 1136-44.

\section{Engel 2001}

Engel J. A proposed diagnostic scheme for people with epileptic seizures and with epilepsy: report of the ILAE Task
Force on Classification and Terminology. Epilepsia 2001;42 (6):796-803.

\section{Engel 2006}

Engel J. Report of the ILAE Classification Core Group. Epilepsia 2006;47(9):1558-68.

\section{Fisher 2005}

Fisher RS, van Emde Boas W, Blume W, Elger C, Genton $P$, Lee $\mathrm{P}$, et al.Epileptic seizures and epilepsy: definitions proposed by the International League Against Epilepsy (ILAE) and the International Bureau for Epilepsy (IBE). Epilepsia 2005;46(4):470-2.

\section{Fogelholm 1981}

Fogelholm R. Subarachnoid hemorrhage in middle-Finland: incidence, early prognosis and indications for neurosurgical treatment. Stroke 1981;12(3):296-301.

\section{Hart 2011}

Hart Y, Sneade M, Birks J, Rischmiller J, Kerr R, Molyneux A. Epilepsy after subarachnoid hemorrhage: the frequency of seizures after clip occlusion or coil embolization of a ruptured cerebral aneurysm: results from the International Subarachnoid Aneurysm Trial. Journal of Neurosurgery 2011;115(6):1159-68.

Hoh 2011

Hoh BL, Nathoo S, Yueh-Yun C, Mocco J, Barker FG. Incidence of seizures or epilepsy after clipping or coiling of ruptured and unruptured cerebral aneurysms in the Nationwide Inpatient Sample Database: 2002-2007. Neurosurgery 2011;69:644-50.

\section{King 1994}

King WA, Martin NA. Critical care of patients with subarachnoid hemorrhage. Neurosurgery Clinics of North America 1994;5(4):767-87.

\section{Lanzino 2011}

Lanzino G, D'Urso PI, Suarez J. Seizures and anticonvulsants after aneurysmal subarachnoid hemorrhage. Neurocritical Care 2011;15(2):247-56.

\section{Lefebvre 2009}

Lefebvre C, Manheimer E, Glanville J. Chapter 6: Searching for studies. In: Higgins JPT, Green S (editors). Cochrane Handbook for Systematic Reviews of Interventions Version 5.0.2 [updated September 2009]. The Cochrane Collaboration, 2009. Available from www.cochranehandbook.org.

\section{Lin 2003}

Lin CL, Dumont AS, Lieu AS, Yen CP, Hwang SL, Kwan $\mathrm{AL}$, et al.Characterization of perioperative seizures and epilepsy following aneurysmal subarachnoid hemorrhage. Journal of Neurosurgery 2003;99(6):978-85.

\section{Lin 2008}

Lin YJ, Chang WN, Chang HW, Ho JT, Lee TC, Tsai NW, et al.Risk factors and outcome of seizures after spontaneous aneurysmal subarachnoid hemorrhage. European Journal of Neurology 2008;15(5):451-7. 


\section{Molyneux 2005}

Molyneux AJ, Kerr RS, Yu LM, Clarke M, Sneade M, Yarnold JA, et al.International subarachnoid aneurysm trial (ISAT) of neurosurgical clipping versus endovascular coiling in 2143 patients with ruptured intracranial aneurysms: a randomised comparison of effects on survival, dependency, seizures, rebleeding, subgroups, and aneurysm occlusion. Lancet 2005;366(9488):809-17.

\section{Ohkuma 1990}

Ohkuma A, Kawaguchi M, Sugimoto S, Yanagimoto M, Hattori T. Epilepsy after operation for ruptured intracranial aneurysm. No Shinkei Geka. Neurological Surgery 1990;18 (8):729-34.

\section{Ohman 1990}

Ohman J. Hypertension is a risk factor for epilepsy after aneurysmal subarachnoid hemorrhage and surgery. Neurosurgery 1990;27(4):578-81.

Olafsson 2000

Olafsson E, Gudmundsson G, Hauser WA. Risk of epilepsy in long-term survivors of surgery for aneurysmal subarachnoid hemorrhage: a population-based study in Iceland. Epilepsia 2000;41(9):1201-5.

Pinto 1996

Pinto AN, Canhao P, Ferro JM. Seizures at the onset of subarachnoid haemorrhage. Journal of Neurology 1996;243 (2):161-4.

\section{Qureshi 2005}

Qureshi AI, Suri MF, Nasar A, Kirmani JF, Divani AA, $\mathrm{He} \mathrm{W}$, et al.Trends in hospitalization and mortality for subarachnoid hemorrhage and unruptured aneurysms in the United States. Neurosurgery 2005;57(1):1-8.

\section{Riordan 2010}

Riordan KC, Wingerchuk DM, Wellik KE, Zimmerman RS, Sirven JI, Noe KH, et al.Anticonvulsant drug therapy after aneurysmal subarachnoid hemorrhage: a critically appraised topic. Neurologist 2010;16(6):397-9.

\section{Steiner 2006}

Steiner T, Kaste M, Forsting M, Mendelow D, Kwiecinski $\mathrm{H}$, Szikora I, et al. Recommendations for the management of intracranial haemorrhage - part I: spontaneous intracerebral haemorrhage. The European Stroke Initiative Writing Committee and the Writing Committee for the EUSI Executive Committee. Cerebrovascular Diseases 2006; 22(4):294-316.

Sundaram 1986

Sundaram MB, Chow F. Seizures associated with spontaneous subarachnoid hemorrhage. Canadian Journal of Neurological Science 1986;13(3):229-31.

\section{Van Gijn 2001}

Van Gijn J, Rinkel GJE. Subarachnoid haemorrhage: diagnosis, causes and management. Brain 2001;124(Pt 2): 249-78.

\section{Varelas 2004}

Varelas PN, Mirski MA. Management of seizures in critically ill patients. Current Neurology and Neuroscience Reports 2004;4(6):489-96.

\section{Vespa 2005}

Vespa P. Continuous EEG monitoring for the detection of seizures in traumatic brain injury, infarction, and intracerebral hemorrhage: "to detect and protect". Journal of Clinical Neurophysiology 2005;22(2):99-106.

* Indicates the major publication for the study 


\section{CHARACTERISTICS OF STUDIES}

\section{Characteristics of excluded studies [ordered by study ID]}

\begin{tabular}{|c|c|}
\hline Study & Reason for exclusion \\
\hline Chumnanvej 2007 & $\begin{array}{l}\text { Not a randomised controlled trial. Patients allocated to short ( } 3 \text { days) or longer-term (until hospital dis- } \\
\text { charge) phenytoin treatment with no comparison with placebo }\end{array}$ \\
\hline Lewis 2009 & Retrospective analysis examining levetiracetam and phenytoin in seizure prophylaxis \\
\hline Murphy-Human 2011 & $\begin{array}{l}\text { Not a randomised controlled study, retrospective analysis of seizure recurrence based on extended phenytoin } \\
\text { use versus } 3 \text { days of levetiracetam }\end{array}$ \\
\hline Naidech 2005 & $\begin{array}{l}\text { Not a randomised controlled trial. Calculation of phenytoin "burden" based on average serum levels and } \\
\text { functional and cognitive outcomes then assessed }\end{array}$ \\
\hline Rapaport 2012 & $\begin{array}{l}\text { Retrospective analysis of the outcome of antiepileptics used in non-traumatic intracranial haemorrhage, not } \\
\text { a randomised controlled trial }\end{array}$ \\
\hline Rhoney 2000 & Retrospective analysis of patient charts, not a randomised controlled trial \\
\hline Rosengart 2007 & $\begin{array}{l}\text { Retrospective analysis of AED prescribing patterns in patients randomised to tirilizad assessing neurological } \\
\text { outcome and in-hospital complications. Not a randomised controlled trial of AED medication }\end{array}$ \\
\hline Szaflarski 2010 & $\begin{array}{l}\text { Randomised single blind trial, but compared levetiracetam with phenytoin rather than placebo; } 89 \% \text { of } \\
\text { patients with traumatic brain injury rather than subarachnoid haemorrhage }\end{array}$ \\
\hline
\end{tabular}




\section{DATAANDANALYSES}

This review has no analyses.

\section{CONTRIBUTIONSOFAUTHORS}

Richard Marigold and Joseph Kwan undertook the literature search, Divya Tiwari and Albrecht Gunther provided expert opinion and editorial support. All authors contributed to the final manuscript.

\section{DECLARATIONSOF INTEREST}

None known

\section{SOURCES OF SUPPORT}

\section{Internal sources}

- University of Southampton, UK.

\section{External sources}

- No sources of support supplied

\section{INDEX TERMS}

\section{Medical Subject Headings (MeSH)}

Anticonvulsants [* therapeutic use]; Secondary Prevention [* methods]; Seizures [etiology; * prevention \& control]; Subarachnoid Hemorrhage [* complications]

\section{MeSH check words}

Humans 